\title{
Ingestion and impact of microplastics on arctic Calanus copepods
}

\author{
Rocío Rodríguez-Torres $^{\mathrm{a}, *}$, Rodrigo Almeda ${ }^{\mathrm{a}, \mathrm{d}}$, Michael Kristiansen ${ }^{\mathrm{b}}$, Sinja Rist ${ }^{\mathrm{a}, \mathrm{c}}$, \\ Mie S. Winding ${ }^{\mathrm{b}}$, Torkel Gissel Nielsen ${ }^{\mathrm{a}}$ \\ ${ }^{a}$ National Institute of Aquatic Resources, Technical University of Denmark, Kemitorvet, Kongens Lyngby, Denmark \\ ${ }^{\mathrm{b}}$ Greenland Climate Research Centre, Greenland Institute of Natural Resources, Kivioq 2, Nuuk, Greenland \\ ${ }^{\mathrm{c}}$ Department of Environmental Engineering, Technical University of Denmark, Bygningstorvet, Kongens Lyngby, Denmark \\ ${ }^{\mathrm{d}}$ Marine Ecophysiology Group (EOMAR), IU- ECOAQUA, University of Las Palmas de Gran Canaria, Canary Islands, Spain
}

\section{A R T I C L E I N F O}

\section{Keywords:}

Microplastics

Arctic copepods

Microplastic ingestion

Fecal pellet production

Egg production

\begin{abstract}
A B S T R A C T
Microplastics (MPs) are contaminants of emerging concern in the Arctic, but knowledge of their potential effects on Arctic plankton food webs remains scarce. We experimentally investigated ingestion and effects of MPs (20 $\mu \mathrm{m}$ polyethylene spheres) on the arctic copepods Calanus finmarchicus, C. glacialis and C. hyperboreus. These species dominate arctic zooplankton biomass and are relevant target species to investigate the potential impacts of MPs on the Arctic marine ecosystem. Females of each species were exposed to two concentrations of MPs (200 and 20,000 MPs L $\mathrm{M}^{-1}$ ) in combination with different food (diatom) concentrations, reflecting high (3000-5000 cells $\mathrm{mL}^{-1}$, spring phytoplankton bloom) and low (50-500 cells $\mathrm{mL}^{-1}$, pre/post bloom) food conditions. MPs did not affect negatively fecal pellet production rates in any of the species at the studied exposure concentrations. However, egg production rates of copepods exposed to MPs were 8 times higher compared with the controls, which suggests that MP exposure can cause stress-induced spawning in arctic copepods. Microscopic examination of the fecal pellets confirmed ingested MPs in the three species (up to aprox. $1000 \mathrm{MPs}^{-1} \mathrm{~d}^{-1}$ ). The number of MPs per pellet decreased exponentially with increasing food concentration. The daily ingestion of MPs per copepod was higher at low- food concentrations (250-500 cells $\mathrm{mL}^{-1}$ ). At our exposure conditions, the presence of MPs inside $C$. hyperboreus fecal pellets did not affect their sinking rates. Overall, our experimental research show that 1) acute exposure to virgin polyethylene MPs has a low impact on arctic Calanus species at environmentally relevant MP concentrations, independent of food availability, and 2) arctic copepods influence the environmental fate of plankton-sized MPs by exporting buoyant MPs from the surface layer to the sea floor via fecal pellets.
\end{abstract}

\section{Introduction}

Microplastics (MPs, plastic particles $<5 \mathrm{~mm}$ ) are found worldwide (Moore, 2008; Arthur et al., 2008; Law and Thompson, 2014), even in the remote polar ecosystems (Obbard et al., 2014; Peeken et al., 2018). In fact, Arctic sea ice and snow currently contain extremely high concentrations of MPs, $>10,000$ plastic particles $L^{-1}$ (Peeken et al., 2018; Bergmann et al., 2019). Moreover, the highest global concentration of plastic fibers in surface waters has been found in the Arctic (Barrows et al., 2018). Considering global warming-induced stressors in the Arctic, there is a rising concern about the potential impacts of MPs in the Arctic ecosystems (AMAP, 2017). MPs have been trapped in sea ice for decades. Accelerated melting due to global warming would increase the release of MPs to the surrounding waters, increasing the exposure of arctic biota to MPs (Obbard et al., 2014). Furthermore, the decrease of sea ice cover (Arrigo et al., 2008; Stroeve et al., 2012) facilitates anthropogenic activities such as maritime transportation, fisheries and resources exploitation (Dalsøren et al., 2007; Melia et al., 2016). These activities may potentially increase plastic pollution in the sensitive arctic ecosystems.

A large proportion of MPs in the environment are similar in size to phytoplankton (Enders et al., 2015), which makes them bioavailable for a broad range of pelagic marine organisms (Lusher et al., 2015), including planktonic copepods (Cole et al., 2013). Copepods are the most abundant animals (metazoans) in the ocean and they play a pivotal role in the marine food web, both as grazers of phytoplankton and as prey for higher trophic levels (e.g. fish; Castonguay et al., 2008). It has been documented that copepods ingest MPs and that high MP

\footnotetext{
* Corresponding author at: Kemitorvet, Building 202, 2800, Kgs Lyngby, Denmark.

E-mail address: rtor@aqua.dtu.dk (R. Rodríguez-Torres).
} 
concentrations negatively affect their grazing, reproduction and lipid content (e.g., Cole et al., 2013, 2016; Raju et al., 2019). However, knowledge of the potential impacts of MPs on arctic copepods is lacking (AMAP, 2017), particularly in relation to the seasonal change in food availability, which is a crucial feature of the arctic ecosystem (Nielsen and Hansen, 1995; Rysgaard et al., 1999 Leu et al., 2015). Additionally, copepod fecal pellets play an important role in the export of organic matter from the productive surface layers to the sediments (Turner, 2015). This process could be impacted by the presence of MPs inside the fecal pellets (Coppock et al., 2019; Cole et al., 2016). The ingestion and packaging of MPs into fecal pellets may promote the vertical exportation of MPs. In turn, low-density MPs may alter the buoyancy of fecal pellets, affecting the sinking velocity of organic matter and therefore the carbon-sequestering pump (Cole et al., 2016). Knowledge of interactions between arctic zooplankton and MPs under more environmentally relevant conditions is needed to evaluate the role of arctic zooplankton on the fate of plastic pollution in the arctic marine ecosystem.

This study aims to evaluate the acute impact of plankton-sized MPs $(20 \mu \mathrm{m})$ on the key arctic copepods: Calanus finmarchicus, C. glacialis and C. hyperboreus. These Calanus species represent $80 \%$ of arctic zooplankton biomass (Madsen et al., 2008) and influence carbon sequestration by vertical exportation of large, fast-sinking fecal pellets (Turner, 2015). Given the strong seasonality of trophic conditions in the Arctic, we experimentally investigated the impact of virgin MPs on arctic copepods under two food conditions: high food (phytoplankton bloom scenario) and low food availability (pre/post bloom scenarios). For a given MP concentration, we hypothesize that ingestion and sub-lethal effects of MPs on copepods depends on the food concentration; specially we expect a higher impact of MPs at low prey:MP ratio, when copepod clearance rates are higher. First, we estimated the influence of food concentration on the impact of MPs on fecal pellet and egg production rates. Secondly, we investigated MP ingestion in relation to food concentration. Lastly, we tested if the presence of MPs inside the fecal pellets affects their sinking rates.

\section{Material and methods}

\subsection{Collection of experimental organisms}

The copepods were collected from Western Greenland waters during a cruise with the research vessel R/V SANNA in May 2019. Hydrography and environmental conditions of the sampling area during our study is presented in Rist et al. (2020). Calanus hyperboreus females were obtained from zooplankton samples collected with a large ring-net of $2 \mathrm{~m}$ diameter equipped with black netting by oblique tows (150 $\mathrm{m}$ depth) at a speed of 2 knots outside the Nuup Kangerlua fjord, on Fyllas Bank (N $64^{\circ} 03^{\prime} 24^{\prime \prime} \mathrm{N}, 52^{\circ} 10^{\prime} 12^{\prime \prime} 64^{\circ} \mathrm{W}$ ). C. glacialis and C. finmarchicus were obtained from zooplankton samples collected in the Nuup Kangerlua fjord using two gear types: a Bongo net with a mesh size of $500 \mu \mathrm{m}$ and a WP-2 net of $200 \mu \mathrm{m}$ mesh size with a large, non-filtering cod end. On deck, the samples collected in the cod ends were emptied in thermo-boxes filled with in situ seawater. Onboard, we sorted and identified the females of the target species ( $C$. finmarchicus and C. glacialis) under a microscope according to criteria in Nielsen et al., 2014. Identified females were immediately transferred to glass beakers containing surface water and kept in trays with ice. Afterwards, the females were stored in a temperature-controlled room in the vessel at $2^{\circ} \mathrm{C}$ in $20 \mathrm{~L}$ cold boxes filled with filtered seawater (FSW) with gentle aeration. They were fed with the diatom Thalassiosira weissflogii ad libitum until returning to the laboratory on land. Once in the harbor, the transfer of copepods from the cold room at the vessel to the cold room at the laboratory was conducted in large thermo-boxes $(70 \mathrm{~L})$ in less than 1 h. The phytoplankton species used to feed the copepods during the experiments was $T$. weissflogii (average equivalent spherically diameter $(E S D)=11.6 \mu \mathrm{m})$. The diatom culture was kept in exponential growth at $15^{\circ} \mathrm{C}$ in culture in $\mathrm{B} 1$ medium (Hansen, 1989), grown in a 12:12 light: dark cycle and constant aeration.

\subsection{MP type and preparation of MP suspensions}

Clear polyethylene (PE) spherical particles with a density of $0.96 \mathrm{~g}$ $\mathrm{cm}^{-3}$ (Cospheric $\AA$ ), supplied as a dry powder, were used in the experiments. Approximately $1 \mathrm{mg}$ of powder was suspended in $250 \mathrm{~mL}$ glass bottles containing distilled water with $0.01 \%$ Tween 80 and mixed through vigorous shaking and rotation of the bottles from that stock suspension $\left(5 \times 10^{5} \mathrm{MPs} \mathrm{mL}^{-1}\right)$, the concentration and size of the particles were measured using a Beckman Multisizer III Coulter Counter. The particles had a size range of 13.9-30.3 $\mu \mathrm{m}$, and the mean ESD was $20.7 \mu \mathrm{m}$. From the stock suspension, we prepared two diluted "working suspensions" $\left(10^{3}-10^{4}\right.$ MPs $\left.\mathrm{mL}^{-1}\right)$, one for each exposure level of MPs (see treatments below). The absence of MP aggregates and the concentration of MPs in the working solutions was verified by manual counting under an inverted microscope with Sedgewick-Rafter counting chambers.

\subsection{Experimental set up}

An overview of the exposure treatments and analyses is presented in Fig. 1.

The copepods were exposed to the following treatments:

1) Control (no MPs) with low food concentrations (LF).

2) Control (no MPs) with high food concentrations (HF).

3) Low MPs (200 MPs L ${ }^{-1}$ ) with low food concentrations (LF).

4) Low MPs (200 MPs L ${ }^{-1}$ ) with high food concentrations (HF).

5) High MPs (20,000 MPs L ${ }^{-1}$ ) with low food concentrations (LF).

6) High MPs (20,000 MPs L ${ }^{-1}$ ) with high food concentrations (HF).

The size of the copepod and the concentrations of phytoplankton used in the low (LF: $50-500$ cells $\mathrm{mL}^{-1}$ ) and high (HF: $3000-5000$ cells $\mathrm{mL}^{-1}$ ) food treatments are indicated in Table 1 . In terms of phytoplankton abundance, the high and low diatom concentrations tested can be expected during bloom and pre/post bloom conditions, respectively (Juul-Pedersen et al., 2015; Arendt et al., 2010; Tang et al., 2011).

Prior to the experiments the copepods were kept in a temperaturecontrolled room at $2^{\circ} \mathrm{C}$ and fed with T. weissflogii ad libitum. Experiments were conducted in $600 \mathrm{~mL}$ Pyrex glass bottles with a lid sealed with polytetrafluoroethylene (PTFE) protection. Four replicates per treatment were conducted, the number of copepod females incubated per bottle were 4 for C. finmarchicus and C. glacialis and 2 for C. hyperboreus. The three Calanus species differ in size. C. hyperboreus is $\sim 3$ times larger than C. glacialis and C. finmarchicus, and C. glacialis is slightly larger than $C$. finmarchicus (Table 1 ).

The bottles were filled with $0.2 \mu \mathrm{m}$ FSW at $30 \%$ salinity and the copepods were added. Subsequently, an aliquot of the diatom stock culture and the corresponding MP working suspension were pipetted to each bottle to ensure the desired exposure concentrations for each treatment (Table 1).Tween 80 alone was added to the control bottles at the same concentration than in the experimental bottles. The final concentration of Tween in the incubation bottles was approx. 0.00001 $\%$. Before adding the aliquot of diatoms, the concentration of diatoms in the stock culture was determined under an inverted microscope using Sedgewick-Rafter counting chambers.

Finally, the bottles were filled up with FSW, closed and mounted on a plankton wheel ( $1 \mathrm{rpm}$ ) in a temperature-controlled room at $2^{\circ} \mathrm{C}$ in dark.

The exposure media were renewed daily for 6 days. After $24 \mathrm{~h}$, the content from the bottles was filtered through a $40 \mu \mathrm{m}$ mesh sieve to collect the copepods, eggs and fecal pellets. The copepods were checked for survival and gently transferred to a new bottle with new exposure medium. The concentrated eggs and fecal pellets were transferred to petri dishes by rinsing and fixed with Lugol's solution (1\%) for later quantification and analysis. 


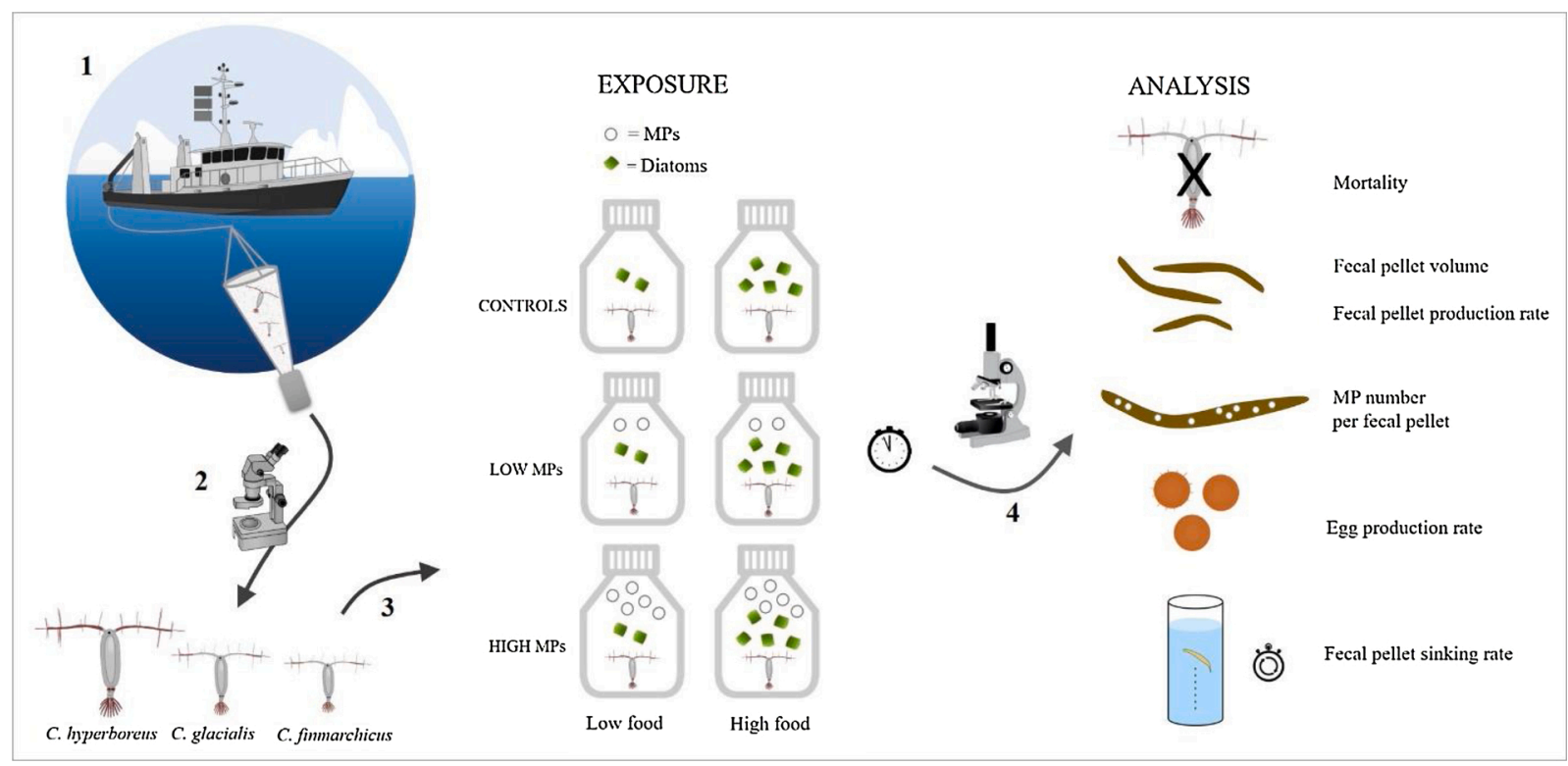

Fig. 1. Schematic overview of the experiment and subsequent analyses used to investigate the impact of MPs (20 $\mu$ m polyethylene spheres) on arctic Calanus copepods. Animals were exposed to different combinations of 0.2 (low) or 20 (high) MPs mL ${ }^{-1}$, and 50-500 (low food) or 3000-5000 (high food) algal cells $\mathrm{mL}^{-1}$ for 6 days.

Table 1

Microplastic concentration (MP conc., MPs $\mathrm{L}^{-1}$ ) and food exposure concentrations for the threecopepod species. The food concentration is given in cell concentration (cells $\mathrm{mL}^{-1}$ ) and in biomass $\left(\mu \mathrm{g} \mathrm{C} \mathrm{L}^{-1}\right.$ ) representing pre/post bloom (low food) and bloom (high food) conditions. The conversion from cell to carbon for T. weissflogii was calculated according to Henriksen et al., 2007.

\begin{tabular}{|c|c|c|c|c|c|c|}
\hline \multirow[t]{2}{*}{ Species } & \multirow[t]{2}{*}{$\begin{array}{l}\text { Prosome } \\
\text { length } \\
(\mu \mathrm{m})\end{array}$} & \multicolumn{3}{|c|}{ MP CONC. (MPs L-1) } & \multirow{2}{*}{$\begin{array}{l}\text { LOW } \\
\text { FOOD } \\
\text { (cells } \\
\mathrm{mL}^{-1} \text { ) } \\
(\mu \mathrm{g} \mathrm{C} \mathrm{L} \\
\left.{ }^{1}\right)\end{array}$} & \multirow{2}{*}{$\begin{array}{l}\text { HIGH } \\
\text { FOOD } \\
\text { (cells } \\
\left.\mathrm{mL}^{-1}\right) \\
(\mu \mathrm{g} \mathrm{C} \mathrm{L} \\
\left.{ }^{1}\right)\end{array}$} \\
\hline & & CONTROL & LOW & HIGH & & \\
\hline C. finmarchicus & 2713 & 0 & 200 & 20000 & $\begin{array}{l}50 \\
250 \\
500 \\
6,30 \\
60\end{array}$ & $\begin{array}{l}3000 \\
5000 \\
360 \\
600\end{array}$ \\
\hline C. glacialis & 3301 & 0 & 200 & 20000 & $\begin{array}{l}50 \\
250 \\
500 \\
6,30 \\
60\end{array}$ & $\begin{array}{l}3000 \\
5000 \\
360 \\
600\end{array}$ \\
\hline C. hyperboreus & 7061 & 0 & 200 & 20000 & $\begin{array}{l}250, \\
500 \\
30,60\end{array}$ & $\begin{array}{l}3000 \\
5000 \\
360 \\
600\end{array}$ \\
\hline
\end{tabular}

\subsection{Sample analysis}

We measured the following end-points: survival, fecal pellet production rates (FPPR), fecal pellet volume, volume specific FPPR, egg production rates (EPR), ingestion of MPs and fecal pellet sinking rates (Fig.1).

The fecal pellets and eggs were counted daily using a stereomicroscope to estimate the fecal pellet and egg production rates. To estimate the fecal pellet volume, pictures of approximately 20 fecal pellets per treatment were taken using a Leica DMC camera mounted on a stereomicroscope and the length and width of the fecal pellets were measured using Image J software. The fecal pellet volume was calculated assuming a cylindrical shape.

To quantify the MP ingestion in each treatment, ten intact fecal pellets were randomly selected from all replicates. The fecal pellets were placed in a Sedgewick-Rafter chamber and the number of MPs per fecal pellet counted under an inverted microscope, checking different planes and using a magnification of $200 \times$.

The fecal pellets of $C$. hyperboreus were used to investigate if the presence of MPs inside the fecal pellets influences their sinking velocity. We randomly collected and took pictures of 10 unbroken pellets from each treatment under the inverted microscope. Then, the pellet was gently transferred with a glass pipette to a graduated glass cylinder of $4.9 \mathrm{~cm}$ diameter and $39 \mathrm{~cm}$ height filled with FSW at $15^{\circ} \mathrm{C}$. Once the pellet started sinking, we measured the time that took it to settle $5.25 \mathrm{~cm}$ (distance between two measuring lines) in the water column without touching the walls of the cylinder. Only free-falling fecal pellets were included into the analysis.

At the end of the 6-day exposure, all copepods were photographed with a Leica camera attached to a stereomicroscope. The prosome length and width was measured with image $J$ software and the volume of the prosome was estimated considering an ellipsoidal shape.

\subsection{Statistical analysis}

All data were statistically analyzed using IBM SPSS 25.0. When the data followed the assumptions for parametric tests, a one-way analysis of variances (ANOVA, $\mathrm{p}<0.05$ ) was carried out together with a Bonferroni post hoc test to assess statistical differences between treatments. We used a non-parametric method (Kruskal-Wallis, $\mathrm{p}<0.05$ ) in cases when the data did not follow the parametric assumptions of normality or homogeneity of variances.

\section{Results}

\subsection{Effects of MPs on survival and fecal pellet production rates of arctic Calanus species}

Survival of copepods was not affected by exposure to MPs. The fecal pellet production rate (FPPR, fecal pellets cop. ${ }^{-1} \mathrm{~d}^{-1}$ ) in the treatments with high food concentrations was 3-6 times higher than with low food concentrations (Fig. 2). MP exposure did not affect FPPR in any of the species studied (Fig. 2). We did not find any statistically significant difference between treatments except for $C$. finmarchicus, which showed 


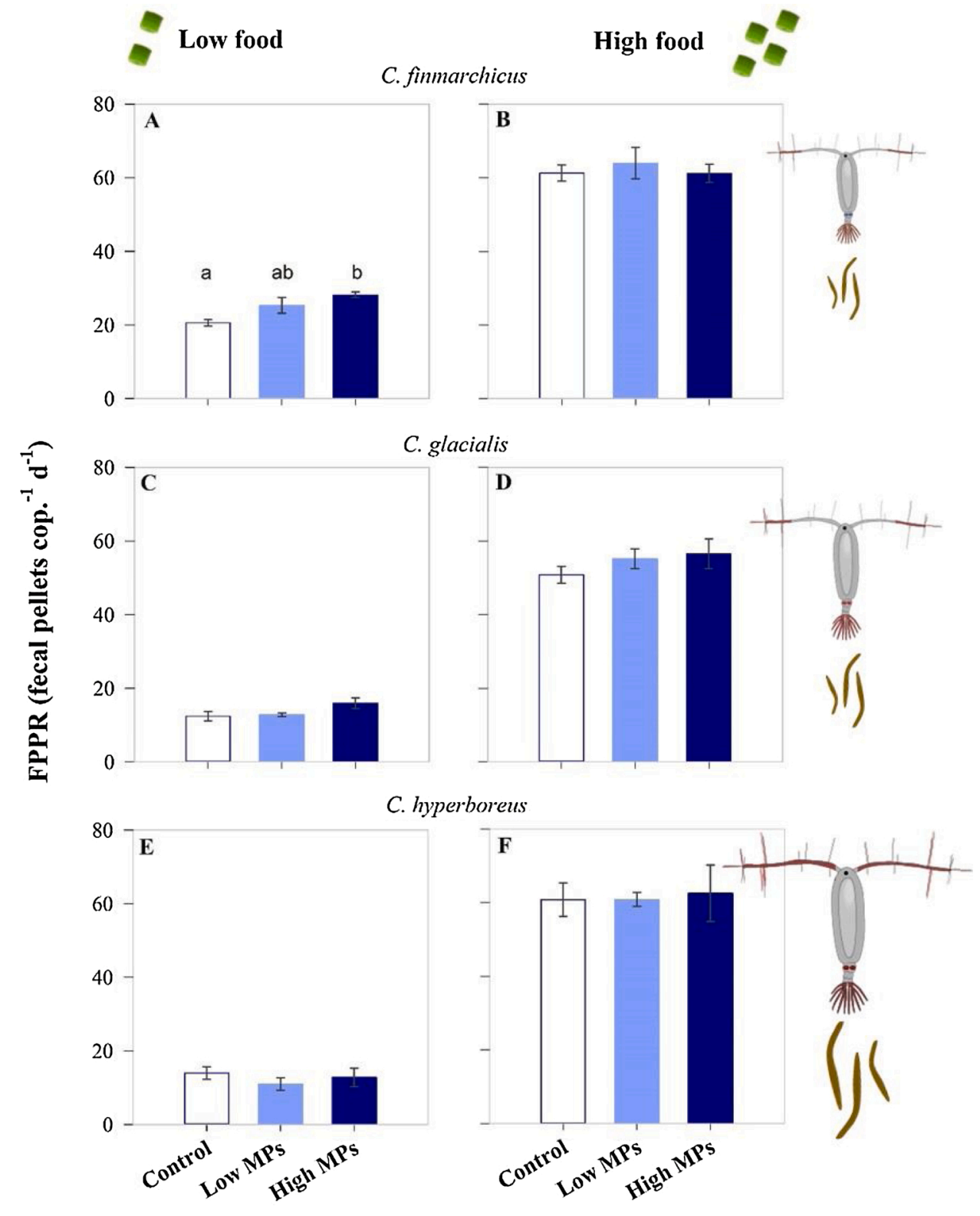

Fig. 2. Fecal pellet production rate (FPPR, fecal pellets copepod ${ }^{-1} \mathrm{~d}^{-1}$ ) of C. finmarchicus (A, B), C. glacialis (C, D) and C. hyperboreus (E, F) in the different treatments: control (no MPs), low MPs $\left(0.2 \mathrm{M} \mathrm{Ps} \mathrm{mL}^{-1}\right.$ ) and high MPs (20 MPs $\mathrm{mL}^{-1}$ ). Error bars indicate the standard error. The lowercase letters (a, b) indicate different statistical groups according to ANOVA and Post-hoc Bonferroni test analysis $(\mathrm{p}<0.05)$. Note that we did not found significant differences among treatments in the results showed in the panels. B-F-.

a small but statistically significant increase in FPPR when exposed to high concentrations of MPs and low food (ANOVA, Bonferreni, $p<0.05$ ) (Fig. 2A). Fecal pellet volume $\left(\mathrm{mm}^{3}\right)$ of $C$. finmarchicus was not affected by MPs in any of the treatments (Kruskal-Wallis, p > 0.05) (Fig. 3 A). However, the fecal pellet volume in C. glacilis and C. hyperboreus showed some small but statistically significant differences between the control and MP treatments (Kruskal-Wallis, $\mathrm{p}<0.05$ ) (Fig. 3B, 3C). Considering the fecal pellet size, the volume of fecal pellet produced daily (Vol.FPPR, $\mathrm{mm}^{3} \operatorname{cop}^{-1} \mathrm{~d}^{-1}$ ) increased with food concentration for all treatments (Fig. 3 D-F). We did not find significant differences in Vol.-FPPR between the control and treatments with MPs for most tested concentrations (ANOVA, p < 0.05) (Fig. 3D). Hence, all the data were fitted to a Michaelis-Menten model (Eq. 1).

$\mathrm{P}=\mathrm{B}_{\max } * \mathrm{C} / \mathrm{C}_{50}+\mathrm{C}$

Where, $P$ is the Vol.-FPPR, $B_{\max }$ is the saturation level, $C$ is the food concentration and $C_{50}$ is the concentration at which $50 \%$ of the FPPR is reached. The equations for each species are presented in the figure panels (Fig. 3 D-F).
3.2. Effects of MPs on egg production rates (EPR) of arctic Calanus species

C. hyperboreus females do not produce eggs in May, hence only EPR of $C$. finmarchicus and C. glacialis were measured (Fig. 4). Accumulative EPR for $C$. finmarchicus was $\sim 3$ times higher than for C. glacialis (Fig. 4). EPR increased at high food concentrations in both species (Fig. 4). We found higher production rates in the treatments with MPs (Fig. 4 A-C), with the exception of $C$. glacialis at high food concentration (Fig. 4D). Although the EPR was low at low food concentrations, the increase in EPR after exposure to MPs was more notable at low concentrations (up to 8 times higher) (Fig. $4 \mathrm{~A}, \mathrm{C}$ ). No differences in egg size were observed between the control and the treatments with MPs for $C$. finmarchicus (Fig. 4E).

\subsection{Effect of food concentration on MP ingestion in arctic copepods}

The number of MPs inside the fecal pellets (Fig. 5) decreased exponentially with increasing food concentration, following an exponential decay model (Eq. 2). 


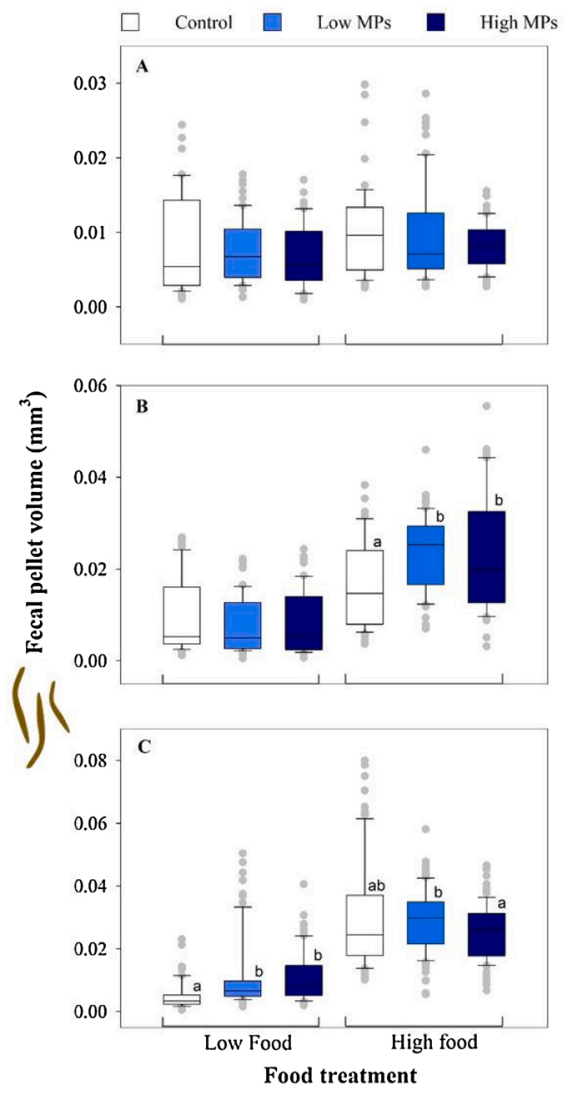

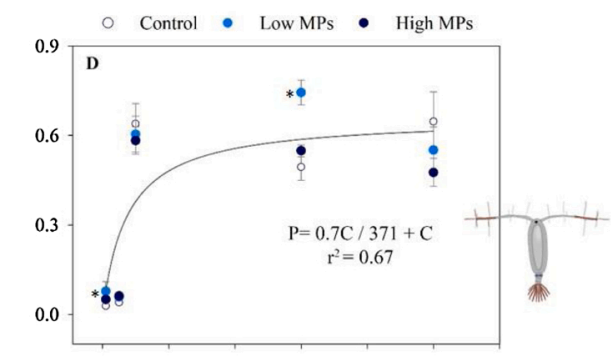
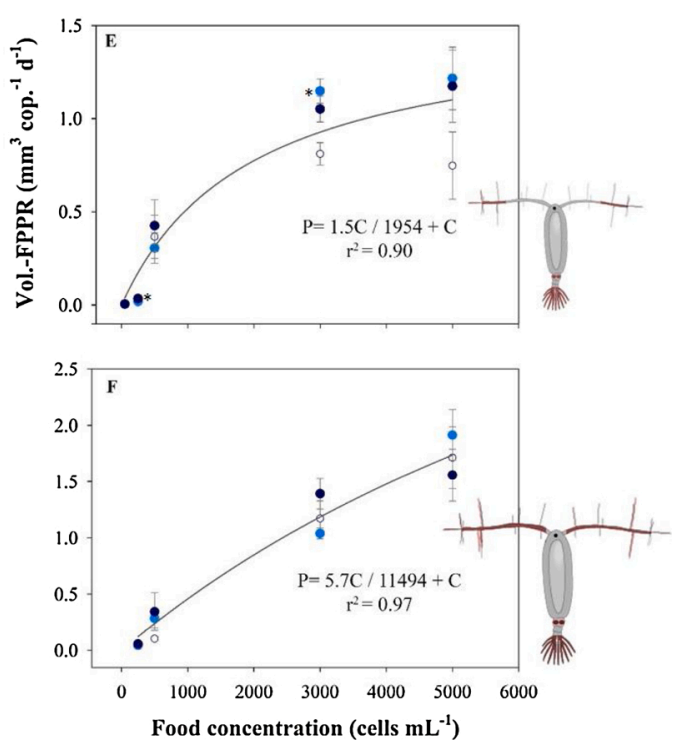

Fig. 3. Left panels: Fecal pellet volume after exposure to the different conditions. Right panels: relationship between volume-specific fecal pellet production rates ( $\mathrm{P}$, Vol.-FPPR, volume of fecal pellets produced per copepod per day, $\mathrm{mm}^{3}$ copepod ${ }^{-1} \mathrm{~d}^{-1}$ ) and food concentration $\left(\mathrm{C}\right.$, cells $\mathrm{mL}^{-1}$ ) for the different MP treatments: control (no MPs), low MPs (0.2 M Ps $\mathrm{mL}^{-1}$ ) and high MPs (20 MPs $\mathrm{mL}^{-1}$ ). C. finmarchicus (A, D), C. glacialis (B, E), C. hyperboreus (C, F). Error bars indicate the standard error. Right panels, a Michaelis Menten model was fixed to all data since no significant differences were observed among treatments in most of the concentrations (equations are given in the panels). The asterisk indicates significant difference (ANOVA, Bonferroni $\mathrm{p}<0.05$ ) between that treatment and the control.
$\mathrm{N}=\mathrm{a}^{*} \exp \left(-\mathrm{b}^{*} \mathrm{C}\right)$

where, $N$ is the number of MPs per fecal pellet, $a$ is the number of MPs per fecal pellet in absence of food $(C=0), b$ is the decay factor and $C$ is the food concentration (cells $\mathrm{mL}^{-1}$ ).

At low MP exposure concentrations, the number of microplastics per pellet at low food concentrations was approximately 3 times higher than at high food concentrations (Fig. 5A, C, E). When exposed to high MP concentrations, the decrease in the number of MPs per pellet in relation to food concentration was even more pronounced, more than one order of magnitude between low and high food concentrations (Fig. 5 B, D, F). The maximum number of MPs per fecal pellets was 143 for C. hyperboreus in conditions of low food and exposed to $20 \mathrm{MPs} \mathrm{mL}^{-1}$. In terms of MP ingestion rates, $C$. hyperboreus was also the species with the highest MP ingestion, up to ca. 1000 MPs per copepod per day (Table 2).

An estimation of the daily ingestion of MPs based on the content of MPs per pellet and FFPR showed that MP ingestion was higher at high plastic concentrations and varied depending on the food level (Table 2). C. hyperboreus, the largest studied copepod, was the species that ingested the higher amount of MPs per copepod per day, up to approximately $1000 \mathrm{MPs} \mathrm{d}^{-1}$ (Table 2). The maximum ingestion was typically at low food concentrations (250-500 cells $\mathrm{mL}^{-1}$ ) for C. finmarchicus and C. glacialis. However, we did not find any differences in MP ingestion rates between food concentrations for C. hyperboreus (Table 2). Daily mass-specific ingestion rates of plastic ( $\mu g_{\text {plastic }} \mathrm{mgC}_{\text {copepod }} \mathrm{d}^{-1}$ ) varied depending on the species and exposure concentrations, with maximum values found for $C$. finmarchicus at low food concentrations (approx. 25 $\mu \mathrm{g}_{\text {plastic }} \mathrm{mgC}_{\text {copepod }} \mathrm{d}^{-1}$ ) (S.I., Table 1).

\subsection{Effect of MPs on sinking rates of fecal pellets}

Sinking rates of $C$. hyperboreus fecal pellets estimated in the laboratory varied from approx. 30 to $200 \mathrm{~m} \mathrm{~d}^{-1}$ depending on the fecal pellet volume (Fig. 6). We observed a significant positive relationship between sinking rates and fecal pellet volume in the control treatments (Fig.6). However, we did not find any effect of MPs on fecal pellet sinking rates in any of our experimental treatments (Fig. 6).

\section{Discussion}

MPs can have negative physical impacts on marine organisms after ingestion or inhalation, such as gut abrasion, obstruction, decreased assimilation rates and reduced brachial function (Wright et al., 2013; Watts et al., 2016). Additionally, MPs - even virgin MPs - can release potentially toxic "leachates" to aquatic biota (Schiavo et al., 2018; Seuront, 2018). Given the importance of zooplankton in marine ecosystems (Banse, 1995; Turner, 2015; Visser et al., 2017), negative effects of MPs on copepods can impact higher trophic levels, vertical export of organic matter, and carbon sequestration (Cole et al., 2013, 2016; Galloway et al., 2017; Coppock et al., 2019).

\subsection{MP type and exposure levels tested in this study}

The diversity of plastic polymers found in the marine ecosystem is large (Erni-Cassola et al., 2019). The polymer used in this study, polyethylene (PE), is typically the most abundant found in surface waters (Erni-Cassola et al., 2019) and therefore relevant for exposure tests. The size of the MPs tested is also relevant since the size fraction $<25 \mu \mathrm{m}$ is the most abundant in marine environmental samples, including in the Arctic (Enders et al., 2015; Peeken et al., 2018; Bergmann et al., 2019; Rist et al., 2020). Virgin spherical plastic particles as used here serve as a useful model to investigate MP-biota interactions, and have been used in many previous studies (Cole et al., 2013,2015; Setâla et al., 2014; Vroom et al., 2017), allowing comparison between organisms. Yet, more research on field-collected MPs is needed because weathering modifies 


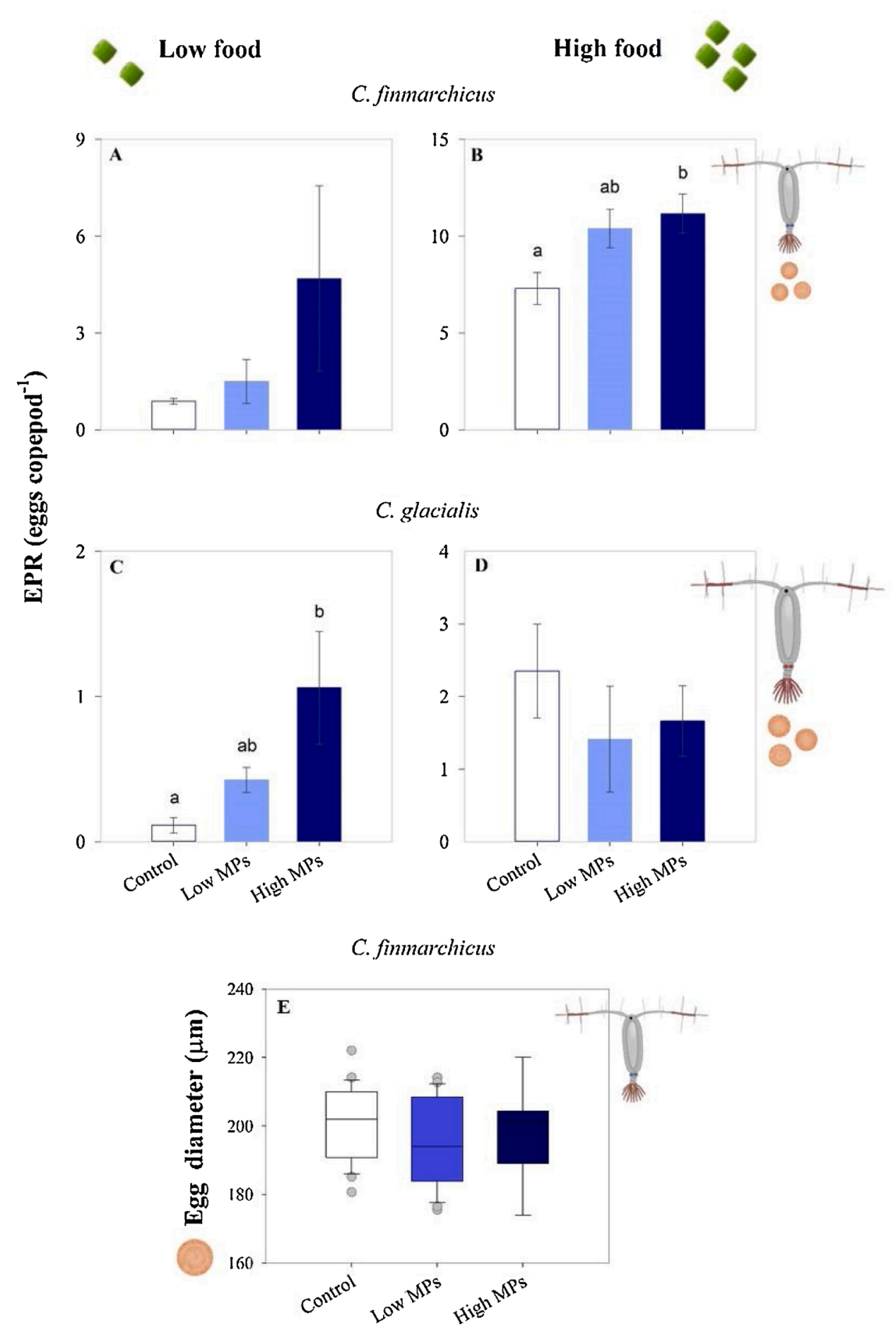

Fig. 4. Cumulative egg production rates (EPR, eggs cop $^{-1}$ ) of C. finmarchicus (A, B) and C. glacialis (C, D) after 6 days of exposure in the different treatments: control (no MPs), low MPs $\left(0.2 \mathrm{M} \mathrm{Ps} \mathrm{mL}^{-1}\right)$ and high MPs (20 MPs mL $\left.{ }^{-1}\right)$. Egg size of $C$. finmarchicus with high food concentrations after exposure to different MP concentrations (E). The error bars represent the standard error. The lowercase letters ( $a$ and $b$ ) indicate different statistical groups according to Post-hoc Bonferroni test analysis ( $\mathrm{p}<0.05$ ).

C. finmarchicus

plastic properties, affecting the interactions between MPs and zooplankton (Vroom et al., 2017; Botterell et al., 2019).

Adverse effects of virgin MPs on planktonic copepods have only been observed at higher concentrations (75-4,000 MPs $\mathrm{mL}^{-1}$ ) than used in this study. With this in mind, the MP exposure levels used in our experiments were selected considering two environmentally relevant concentrations: (1) the maximum concentration found in upper layers of oceanic marine waters to date $\left(0.2 \mathrm{MPs} \mathrm{mL}^{-1}\right)$ (Song et al., 2015); (2) the MP concentrations recently reported in arctic sea ice and snow (20 MPs $\mathrm{mL}^{-1}$ ) (Peeken et al., 2018; Bergmann et al., 2019), which could be temporally found in Arctic sea-ice adjacent waters in an accelerating ice-melting situation induced by climate change (Obbard et al., 2014).

\subsection{Effect of MP exposure on fecal pellet production rates in arctic} Calanus

Fecal pellet production rate (FPPR) is an appropriate proxy for feeding rates in copepods since the egestion rate is directly related to ingested food quantity (Paffenhöfer and Knowles, 1978; Butler and Dam, 1994). Previous studies found a notable decrease in ingestion rates in copepods after exposure to very high concentrations of $7.3 \mu \mathrm{m}$ fluorescent polystyrene (PS) virgin microspheres (e.g., $4000 \mathrm{MPs} \mathrm{mL}^{-1}$, Cole et al., 2013). However, the reduction of ingestion was moderate (6-11\% reduction in cell ingestion) when the $20 \mu \mathrm{m}$ PS MP microspheres concentration was $\leq 100 \mathrm{MPs} \mathrm{mL}^{-1}$ (Cole et al., 2015; Coppock et al., 2019). 


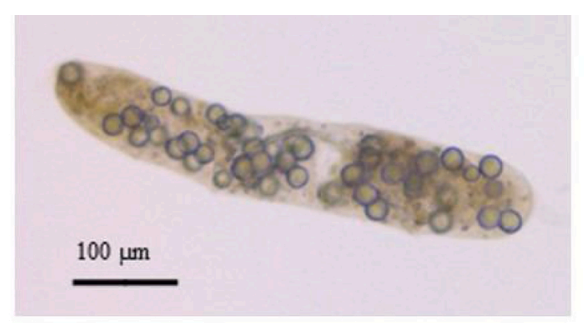

Low MPs
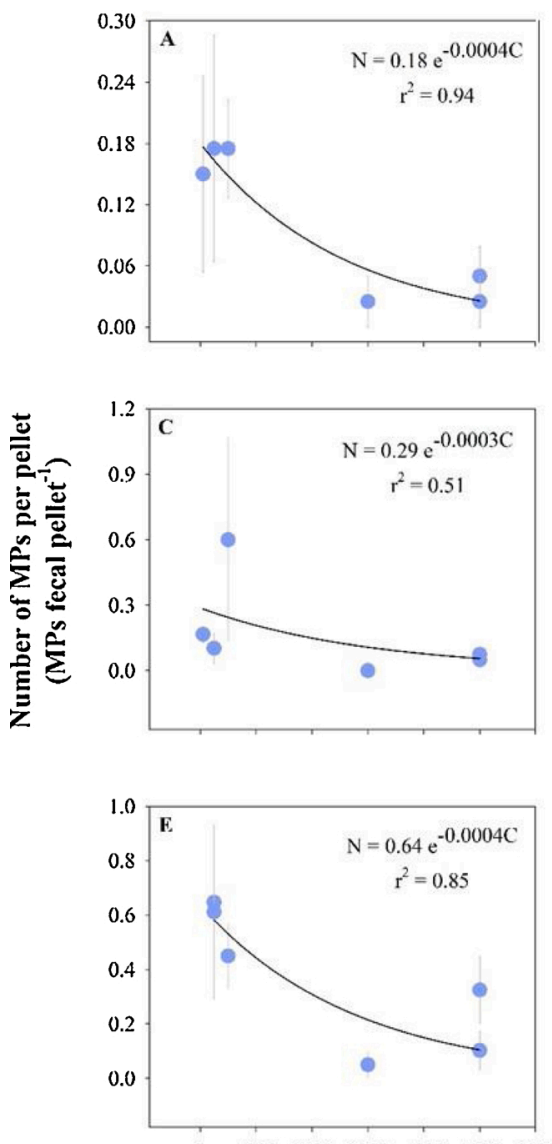

$0 \quad 100020003000400050006000$
High MPs
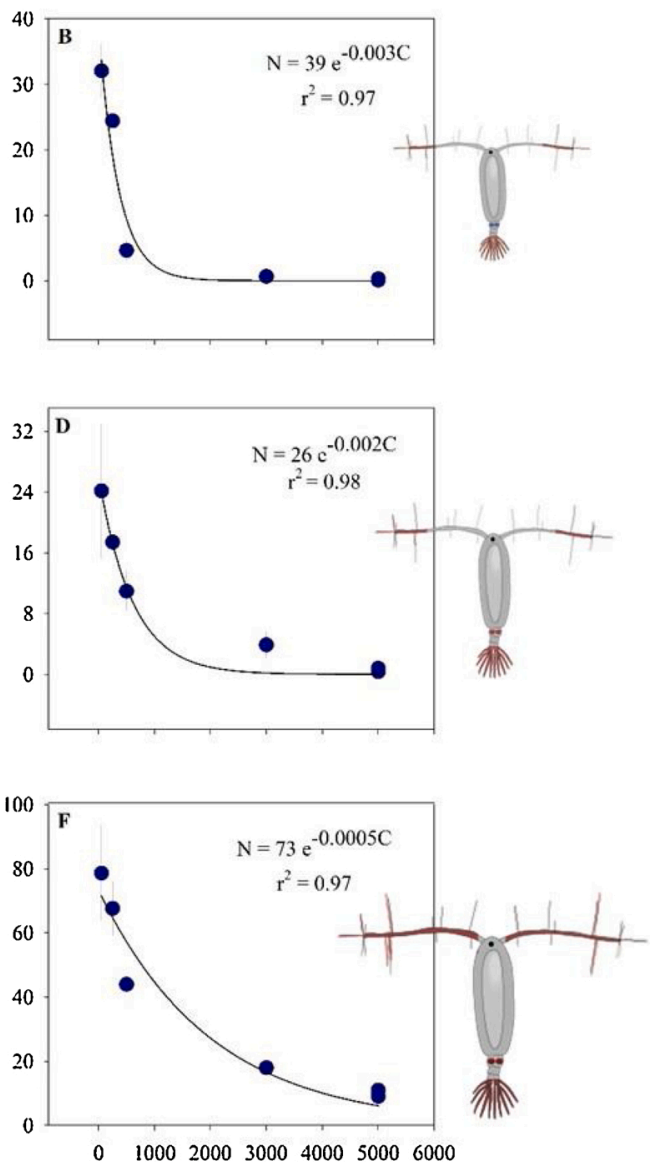

Fig. 5. The photograph in the top is a microscope image showing a Calanus fecal pellet with MPs inside. Relationship between the number of MPs per fecal pellet (N, MPs fecal pellet ${ }^{-1}$ ) and the food concentration (C, cell $\mathrm{mL}^{-1}$ ) for C. finmarchicus (A, B), C. glacialis (C, D) and C. hyperboreus (E, F) after exposure to low $(0.2 \mathrm{M}$ Ps $\mathrm{mL}^{-1}$, left panels) and high (20 MPs $\mathrm{mL}^{-1}$, right panels) concentrations of MPs. The error bars represent the standard error. An exponential decay model was fixed for all the treatments (equations are given in the panels).

Food concentration (cells $\mathrm{mL}^{-1}$ )

Table 2

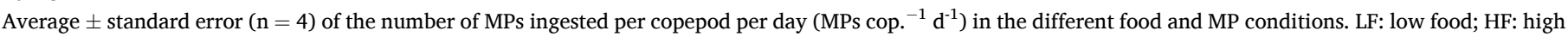
food. The lowercase letters (a, b, c, d) indicate different statistical groups according to ANOVA, post-hoc Bonferroni test (p < 0.05).

\begin{tabular}{|c|c|c|c|c|c|}
\hline \multicolumn{3}{|l|}{ Exposure conditions } & \multirow{2}{*}{$\begin{array}{l}\text { C. finmarchicus } \\
\text { MPs cop. }{ }^{-1} \mathrm{~d}^{-1}\end{array}$} & \multirow{2}{*}{$\begin{array}{l}\text { C. glacialis } \\
\text { MPs cop. }^{-1} \mathrm{~d}^{-1}\end{array}$} & \multirow{2}{*}{$\begin{array}{l}\text { C. hyperboreus } \\
\text { MPs cop. }^{-1} \mathrm{~d}^{-1}\end{array}$} \\
\hline MP level & Food level & Food conc. (cells mL ${ }^{-1}$ ) & & & \\
\hline \multirow{5}{*}{ Low MPs (0.2 M Ps $\left.\mathrm{mL}^{-1}\right)$} & \multirow{3}{*}{ Low food (Pre/post bloom) } & 50 & $1.1 \pm 0.7$ & $0.3 \pm 0.1$ & - \\
\hline & & 250 & $3.3 \pm 0.1$ & $1.0 \pm 0.6$ & $4.3 \pm 1.5$ \\
\hline & & 500 & $7.0 \pm 2.1$ & $13.5 \pm 10.8$ & $6.5 \pm 1.7$ \\
\hline & \multirow{3}{*}{ High food (Bloom) } & 3000 & $1.6 \pm 1.6$ & $0 \pm 0$ & $2.6 \pm 2.6$ \\
\hline & & 5000 & $2.9 \pm 1.1$ & $3.1 \pm 1.0$ & $10.6 \pm 3.4$ \\
\hline \multirow{5}{*}{ High MPs (20 MPs mL ${ }^{-1}$ ) } & & 50 & $292 \pm 55^{a}$ & $46 \pm 34^{\mathrm{a}, \mathrm{b}}$ & - \\
\hline & \multirow[t]{2}{*}{ Low food (Pre/post bloom) } & 250 & $537 \pm 67^{b}$ & $264 \pm 59^{a, c}$ & $700 \pm 89$ \\
\hline & & 500 & $204 \pm 63^{a, c}$ & $226 \pm 67^{\mathrm{a}, \mathrm{c}}$ & $501 \pm 102$ \\
\hline & \multirow{2}{*}{ High food (Bloom) } & 3000 & $36 \pm 8^{c, d}$ & $180 \pm 77^{\mathrm{a}, \mathrm{b}, \mathrm{c}}$ & $991 \pm 262$ \\
\hline & & 5000 & $9 \pm 4^{d}$ & $32 \pm 9^{\mathrm{b}, \mathrm{c}}$ & $626 \pm 92$ \\
\hline
\end{tabular}

At the exposure conditions tested here, MPs did not negatively affect FPPR (nor volume-specific FPPR), showing that virgin MPs did not interfere with ingestion or egestion rates in Arctic Calanus copepods.

\subsection{Effect of MP exposure on egg production rates in arctic Calanus}

The three species used in this study have different reproduction 


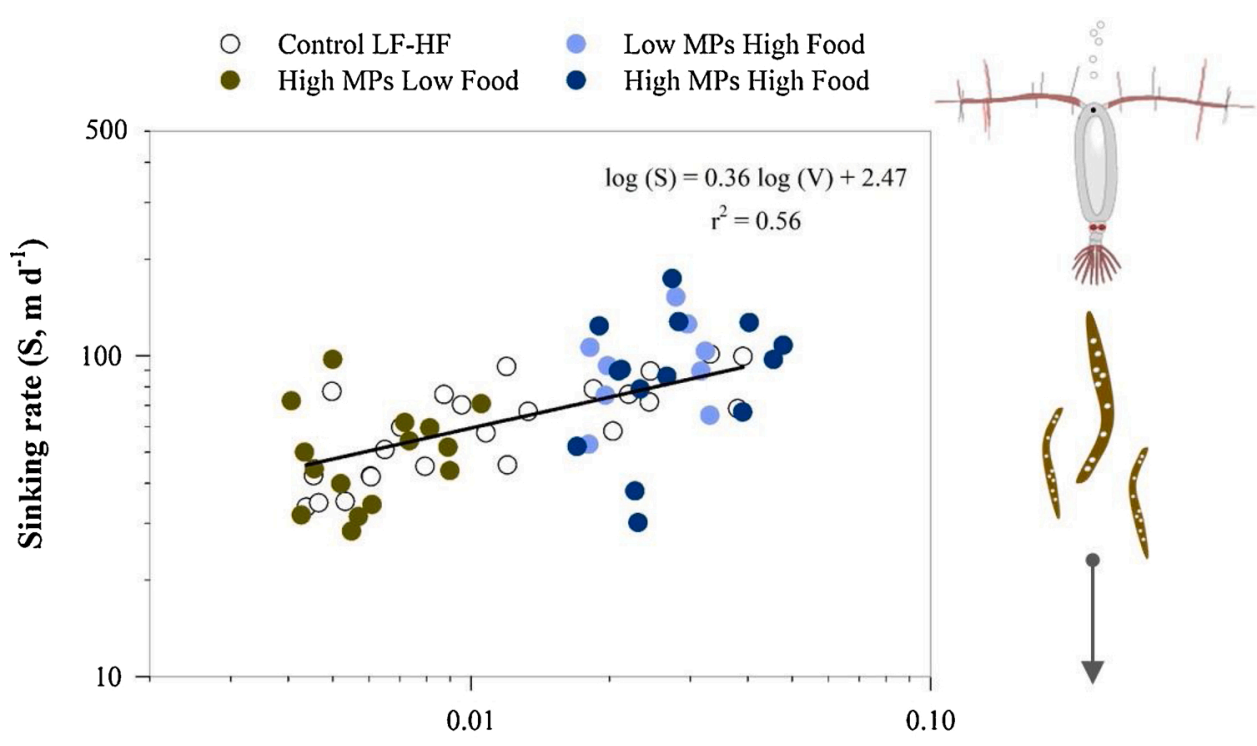

Fig. 6. Relationship between sinking rate $(S, m$ $\left.\mathrm{d}^{-1}\right)$ and fecal pellet volume $\left(\mathrm{V}, \mathrm{mm}^{3}\right)$ of C. hyperboreus for four different treatments. (LF: low food and HF: high food). The blue dots represent treatments with low MPs (0.2 M Ps $\mathrm{mL}^{-1}$, light) and high MPs (20 MPs $\mathrm{mL}^{-1}$, dark). The line represents the linear regression equation fitted to the logarithmically transformed data; the equation is given in the figure. Note that the fecal pellets from the low MPs and low food treatments were not used because they were soft and got broken with the handling.

Fecal pellet volume $\left(\mathrm{V}, \mathrm{mm}^{3}\right)$

strategies. C. finmachicus is mostly an income breeder (Varpe et al., 2009), producing offspring based on concurrent food intake, mainly during the spring phytoplankton bloom. In contrast, $C$. hyperboreus is a capital breeder, meaning that it produces offspring utilizing stored resources (Varpe et al., 2009). C. glacialis has a flexible reproductive strategy depending on the feeding environment (Daase et al., 2013). EPR were lower than observed in other studies (Madsen et al., 2008; Swalethorp et al., 2011) and, as expected, EPR increased with increasing food concentration.

Most previous experimental studies on impacts of MPs on copepods have found either no effects or a decrease in egg production and fecundity, depending on the MP exposure concentration. For example, Cole et al. (2015) did not find any significant effects of $20 \mu \mathrm{m}$ PS microspheres (75 MPs $\mathrm{mL}^{-1}$ ) on $C$. helgolandicus EPR, but the eggs were smaller and the hatching decreased, which caused a negative effect on the overall fecundity. However, we did not find any effect of MPs in C. finmarchicus egg size (Fig. 4E). Interestingly, we found that egg production rates increased after exposure to MPs in three out of four treatments (Fig. 4), suggesting that MPs can trigger stress-induced spawning in arctic copepods. Both natural (e.g., acute changes in temperature and UV light) and anthropogenic stressors (pollution) can induce spawning in marine animals (Loosanoff., 1945; Schreck et al., 2001). As far as we know, this is the first study reporting that MPs can promote stress- induced spawning in marine invertebrates. It is unclear how MP-induced spawning can affect population dynamics. The studied species mainly reproduce during the spring bloom, when nauplii are expected to have enough food, so a mismatch between nauplii and food resources could occur. More research is needed to understand the consequences of MP- induced stress responses on copepods and their population dynamics.

\subsection{Ingestion of MPs in relation to food concentration}

Ingestion of plastic particles by zooplankton in the laboratory is well documented (reviewed in Botterell et al., 2019), and there is some supporting evidence from field studies (Sun et al., 2017; Desforges et al., 2015). Several properties affect the bioavailability of MPs to zooplankton, including the size and concentration of MPs (Botterell et al., 2019). Particles of $20 \mu \mathrm{m}$ diameter are within the prey size-range of the Calanus species (Frost, 1972; Levinsen et al., 2000), and our observation of MPs inside the fecal pellets confirm the ingestion of MPs of this size. As expected, ingestion of MPs increased with increasing MP concentration, independently of food availability (Fig. 5; Table 2). The observed influence of phytoplankton concentration on MP ingestion can be explained by the relationship between copepod clearance rates ("filtration rates") and food concentration (Frost, 1972). Clearance rates decrease with increasing food concentration, which causes a reduction in MPs per pellet observed in our study at high food levels (Fig. 5). The presence of MPs inside fecal pellets, particularly at low food levels, suggests that the studied copepods have a limited capability to avoid the ingestion of small MPs $(20 \mu \mathrm{m})$ in the presence of phytoplankton. However, little is known about mechanistic discrimination and selection of plastic particles of different characteristics.

\subsection{Sinking rates of fecal pellets containing MPS}

Zooplankton fecal pellets play an important role in the recycling and vertical transportation of carbon in the water column (Wieczorek et al., 2019). Cole et al. (2016) found that incorporation of ingested MPs into fecal pellets reduced their sinking rates in the laboratory. In our study, fecal pellet sinking rates increased with increasing pellet volume (depending on food concentrations, Butler and Dam, 1994), but were not affected by the presence of MPs inside the fecal pellets. This discrepancy may be due to differences in MP exposure concentrations between studies, since our MP concentrations were two to two orders of magnitude lower than in Cole et al. (2016) (PS, $20.6 \mu \mathrm{m}, 1.000 \mathrm{MPs}$ $\mathrm{mL}^{-1}$ ). The density of the MPs used in this study was $0.96 \mathrm{~g} \mathrm{~cm}^{-3}$, so they are positively buoyant in seawater. However, in our study MPs only represented a small fraction (from $<1 \%-5 \%$ ) of the total volume of the fecal pellet in the three species. Yet, fecal pellets of $C$. hyperboreus containing MPs can be vertically exported at relatively high rates (up to $100 \mathrm{~m} \mathrm{~d}^{-1}$ at $15^{\circ} \mathrm{C}$ ) due to their large size (up to $3 \mathrm{~mm}$ ). Nevertheless, given the influence of temperature on water viscosity and density, the fecal pellet sinking rates are expected to be slower at in situ temperatures than estimated here in the laboratory at $15^{\circ} \mathrm{C}(\sim 70 \%$ slower at $0{ }^{\circ} \mathrm{C}$ than at $15{ }^{\circ} \mathrm{C}$, Bach et al., 2012).

\subsection{Ecological implications}

Extrapolation of laboratory results to field conditions must always be done cautiously. In the field, interactions between MPs and zooplankton depend on many factors, and some of them (e.g., currents, turbulence and vertical migration) are difficult to simulate in the laboratory. Furthermore, MPs are weathered in the marine environment (e.g, 
formation of biofilms, polymer degradation), which affects the perception, ingestion and effects of MPs on zooplankton (Liu et al., 2020). Nevertheless, exposure experiments under controlled conditions are an essential tool to investigate the impact of MPs on marine biota.

The impact of MPs on Arctic copepods is expected to be minor since MP concentrations currently found in Arctic surface waters are very low, generally $<1 \mathrm{MP} \mathrm{L}^{-1}$ (Lusher et al., 2015; Kanhai et al., 2017). We did not find any negative effects of virgin MPs on FPPR even at high concentrations, and the concentrations of MPs that induce spawning of Calanus were three to four orders of magnitude higher than those we currently reported in marine waters, including West Greenland waters (0.15 MPs L ${ }^{-1}$, Rist et al., 2020). However, considering increasing global plastic production and accelerating global warming, MP pollution could increase in the Arctic, particularly in sea ice adjacent waters, which can become potential hot spots of plastic pollution (Obbard et al., 2014; Coppock et al., 2019; Bergmann et al., 2019). Even though our results suggest that PE virgin MPs spheres alone have a low impact on arctic copepods, the combination of MPs with other stressors (e.g., other pollutants, Almeda et al., 2020) require further investigation to evaluate potential synergetic effects of multiple stressors on the sensitive arctic ecosystem, one of the regions most affected by global warming.

Ingestion of MPs by zooplankton is considered the main entry of MPs into marine food webs and their potential transfer to higher trophic levels (Setälä et al., 2014). Our results suggest that, for a given MP concentration, the ingestion of MPs by zooplankton will be higher during the early post- phytoplankton bloom when the copepods are abundant and their clearance rates are higher due to the low food concentration. MPs had a low impact on the studied copepods, but they could act as vectors of plastic transfer to higher or other trophic levels in different ways: (1) with MPs in the gut when eaten by predators and (2) via fecal pellets. Since gut evacuation time of copepods are fast (from minutes to 2 h, Ellis and Small, 1989; Hansen et al., 1990; Barquero et al., 1998; Maar et al., 2002), MPs would stay in the copepod guts for short periods. However, the residence time of MPs inside the fecal pellets is expected to be longer than in the copepod, which emphasizes the potential role of the fecal pellet in the bio-transfer of MPs in the food webs. Fecal pellets from copepods are an important source of energy for coprophage zooplankton (Paffenhöfer \& Knowless, 1978; Paffenhöfer and Strickland, 1970; Iversen and Poulsen, 2007; Green et al., 1992). Furthermore, some protozoans (e.g, dinoflagellate, Noctiluca scintillans) can feed on fecal pellets (Kiørboe, 2003). However, there is still little experimental and field evidence of the bio-transfer of MPs, either via copepods or fecal pellets, in marine planktonic food webs.

Exportation of MPs via fecal pellets can contribute to the removal of buoyant MPs from surface waters (Cózar et al., 2017). When MP-contaminated fecal pellets reach the seafloor, they can be either ingested by benthic organisms or integrated into the sediments. For example, based on our estimations and after correcting the temperature-effect on sinking rates (Bach et al., 2012), a fecal pellet (volume $=0.05 \mathrm{~mm}^{3}$ ) of $C$. hyperboreus with 20 MPs inside will reach the sea floor (50 m depth, Arendt et al., 2010) in less than 1 day in the sampling site, Fyllas Bank. However, the same fecal pellet would reach the seafloor of Nuup kangerlua fjord (600 m average depth, Weidick et al., 2012) in approx. 10 days. During this time, degradation and recycling of fecal pellets in the water column could affect the vertical exportation and distribution of MPs via fecal pellets. More research and field studies on the role of zooplankton fecal pellets in the distribution of MPs is needed to better understand the ultimate fate of plastic pollution in marine environments.

\section{Conclusions}

Exposure to polyethylene virgin MPs did not affect egestion rates of the three dominant arctic Calanus species. However, high concentrations of MPs caused stress-induced spawning in two of the studied copepod species. Arctic copepods ingested plankton-sized MPs and the uptake depended on the phytoplankton concentration. The presence of MPs in the fecal pellets did not affect their sinking rates. MP-contaminated fecal pellets act as vehicles of MPs, potentially contributing to the distribution and fate of plastic pollution in the environment. Overall, our experimental results suggest that virgin MPs have a low impact on arctic Calanus species considering current environmental concentrations of MPs found in surface waters.

\section{CRediT authorship contribution statement}

Rocío Rodríguez-Torres: Conceptualization, Methodology, Formal analysis, Investigation, Writing - original draft, Writing - review \& editing. Rodrigo Almeda: Conceptualization, Methodology, Formal analysis, Investigation, Writing - original draft, Writing - review \& editing, Project administration, Funding acquisition. Michael Kristiansen: Investigation, Writing - review \& editing. Sinja Rist: Methodology, Formal analysis, Investigation, Writing - review \& editing. Mie S. Winding: Investigation, Methodology, Writing - review \& editing. Torkel Gissel Nielsen: Conceptualization, Writing - review \& editing, Project administration, Funding acquisition.

\section{Declaration of Competing Interest}

The authors declare that they have no known competing financial interests or personal relationships that could have appeared to influence the work reported in this paper.

\section{Acknowledgment}

This investigation was funded by The Danish Center for research into Marine Plastic Pollution ("MarinePlastic") supported by the Velux foundation (Project no. 25084)and a research grant from the Maritime DTU-Orients Fund (project no. 09.12.14 - "Microplastics \& Oil")to RA. This paper was furthermore supported by the H2020 CLAIM project (Cleaning Litter by developing and Applying Innovative Methods in European seas; Grant Agreement No. 774586) to TGN. We thank Tracey Saxby, Integration and Application Network, University of Maryland Center for Environmental Science (http://ian. umces.edu/ imagelibrary/ ) for providing some of the vector graphics used in the figures. We also thank the R/V SANNA crew for their assistance during the cruise.

\section{Appendix A. Supplementary data}

Supplementary material related to this article can be found, in the online version, at doi:https://doi.org/10.1016/j.aquatox.2020.105631.

\section{References}

Almeda, R., Rodriguez-Torres, R., Rist, S., Winding, M.H.S., Stief, P., Hansen, B.H., Nielsen, T.G., 2020. Microplastics do not increase bioaccumulation of petroleum hydrocarbons in Arctic zooplankton but trigger feeding suppression under coexposure conditions. Sci. Total Environ. 751, 141264 https://doi.org/10.1016/j. scitotenv.2020.141264.

AMAP, 2017. AMAP Assessment 2016: Chemicals of Emerging Arctic Concern. Arctic Monitoring and Assessment Programme (AMAP), Oslo, Norway xvi+353pp.

Arendt, K.E., Nielsen, T.G., Rysgaard, S., Tönnesson, K., 2010. Differences in plankton community structure along the Godthåbsfjord, from the Greenland Ice Sheet to offshore waters. Mar. Ecol. Prog. Ser. 401, 49-62. https://doi.org/10.3354/ meps08368.

Arrigo, K.R., van Dijken, G., Pabi, S., 2008. Impact of a shrinking Arctic ice cover on marine primary production. Geophys. Res. Lett. 35, L19603 https://doi.org/ 10.1029/2008GL035028.

Arthur, C., Baker, J., Bamford, H., 2008. Proceedings of the international research workshop on the occurrence, effects and fate of microplastic marine debris. Natl. Oceanic Atmos. Admin. 2009.

Bach, L.T., Riebesell, U., Sett, S., Febiri, S., Rzepka, P., Schulz, K.G., 2012. An approach for particle sinking velocity measurements in the 3-400 $\mu \mathrm{m}$ size range and considerations on the effect of temperature on sinking rates. Mar. Biol. 159, 1853-1864. https://doi.org/10.1007/s00227-012-1945-2. 
Banse, Karl, 1995. Zooplankton: pivotal role in the control of ocean production: I. biomass and production. Ices J. Mar. Sci. 52, 265-277. https://doi.org/10.1016/ 1054-3139(95)80043-3.

Barquero, S., Cabal, J.A., Anadón, R., Fernández, E., Varela, M., Bode, A., 1998. Ingestion rates of phytoplankton by copepod size fractions on a bloom associated with an offshelf front of NW Spain. J. Plankton Res. 20, 957-972. https://doi.org/10.1093/ plankt/20.5.957.

Barrows, A.P.W., Cathey, S.E., Petersen, C.W., 2018. Marine environment microfiber contamination: global patterns and the diversity of microparticle origins. Environ. Pollut. 237, 275-284. https://doi.org/10.1016/j.envpol.2018.02.062.

Bergmann, M., Mützel, S., Primpke, S., Tekman, M.B., Trachsel, J., Gerdts, G., 2019. White and wonderful? Microplastics prevail in snow from the Alps to the Arctic. Sci. Adv. 5 https://doi.org/10.1126/sciadv.aax1157 eaax1157.

Botterell, Z.L.R., Beaumont, N., Dorrington, T., Steinke, M., Thompson, R.C., Lindeque, P. K., 2019. Bioavailability and effects of microplastics on marine zooplankton: review. Environ. Pollut. 245, 98-110. https://doi.org/10.1016/j. envpol.2018.10.065.

Butler, M., Dam, H., 1994. Production rates and characteristics of fecal pellets of the copepod Acartia tonsa under simulated phytoplankton bloom conditions: implications for vertical fluxes. Mar. Ecol. Prog. Ser. 114 (1/2), 81-91. https://doi. org/10.3354/meps114081.

Castonguay, M., Plourde, S., Robert, D., Runge, J.A., Fortier, L., 2008. Copepod production drives recruitment in a marine fish. Can. J. Fish. Aquat. Sci. 65 , 1528-1531. https://doi.org/10.1139/F08-126.

Cole, M., Lindeque, P.K., Fileman, E., Halsband, C., Goodhead, R., Moger, J., Galloway, T.S., 2013. Microplastic ingestion by zooplankton. Environ. Sci. Technol. 47 (12), 6646-6655. https://doi.org/10.1021/es400663f.

Cole, M., Lindeque, P.K., Fileman, E., Halsband, C., Galloway, T.S., 2015. The impact of polystyrene microplastics on feeding, function and fecundity in the marine copepod Calanus helgolandicus. Environ. Sci. Technol. 49 (2), 1130-1137. https://doi.org/ 10.1021/es504525u.

Cole, M., Lindeque, P.K., Fileman, E., Clark, J., Lewis, C., Halsband, C., Galloway, T.S., 2016. Microplastics alter the properties and sinking rates of zooplankton faecal pellets. Environ. Sci. Technol. 50 (6), 3239-3246. https://doi.org/10.1021/acs. est.5b05905 https://.

Coppock, R.L., Galloway, T.S., Cole, M., Fileman, E.S., Queirós, A.M., Lindeque, P.K., 2019. Microplastics alter feeding selectivity and faecal density in the copepod, Calanus helgolandicus. Sci. Total Environ. 687, 780-789. https://doi.org/10.1016/j. scitotenv.2019.06.009.

Cózar, A., Martí, E., Duarte, C.M., García-de-Lomas, J., van Sebille, E., Ballatore, T.J., Eguíluz, V.M., González-Gordillo, J.I., Pedrotti, M.L., Echevarría, F., Troublè, R., Irigoien, X., 2017. The Arctic ocean as a dead end for floating plastics in the North Atlantic branch of the Thermohaline Circulation. Sci. Adv. 3, e1600582 https://doi org $/ 10.1126 /$ sciadv.1600582.

Daase, M., Falk-Petersen, S., Varpe, Ø., Darnis, G., Søreide, J.E., Wold, A., Leu, E., Berge, J., Philippe, B., Fortier, L., 2013. Timing of reproductive events in the marine copepod Calanus glacialis: a pan-Arctic perspective. Can. J. Fish. Aquat. Sci. 70, 871-884. https://doi.org/10.1139/cjfas-2012-0401.

Dalsøren, S.B., Endresen, Ø., Isaksen, I.S.A., Gravir, G., Sørgård, E., 2007. Environmental impacts of the expected increase in sea transportation, with a particular focus on oil and gas scenarios for Norway and northwest Russia. J. Geophys. Res. 112, D02310 https://doi.org/10.1029/2005JD006927.

Desforges, J.P.W., Galbraith, M., Ross, P.S., 2015. Ingestion of microplastics by zooplankton in the northeast Pacific Ocean. Arch. Environ. Contam. Toxicol. 69, 320-330. https://doi.org/10.1007/s00244-015-0172-5.

Ellis, S.G., Small, L.F., 1989. Comparison of gut-evacuation rates of feeding and nonfeeding Calanus marshallae. Mar. Biol. 103, 175-181. https://doi.org/10.1007/ BF00543345.

Enders, K., Lenz, R., Stedmon, C.A., Nielsen, T.G., 2015. Abundance, size and polymer composition of marine microplastics $\geq 10 \mu \mathrm{m}$ in the Atlantic Ocean and their modelled vertical distribution. Mar. Pollut. Bull. 100 (1), 70-81. https://doi.org/ 10.1016/j.marpolbul.2015.09.027.

Erni-Cassola, G., Zadjelovic, V., Gibson, M.I., Christie-Oleza, J.A., 2019. Distribution of plastic polymer types in the marine environment; a meta-analysis. J. Hazard. Mater 369, 691-698. https://doi.org/10.1016/j.jhazmat.2019.02.067.

Frost, B.W., 1972. Effects of size and concentration of food particles on the feeding behavior of the marine planktonic copepod Calanus pacificus. Limnonol. Oceanogr. 17, 805-815. https://doi.org/10.4319/lo.1972.17.6.0805.

Galloway, T., Cole, M., Lewis, C., 2017. Interactions of microplastic debris throughout the marine ecosystem. Nat. Ecol. Evol. 1, 0116. https://doi.org/10.1038/s41559017-0116.

Green, E.P., Harris, R.P., Duncan, A., 1992. The production and ingestion of faecal pellets by nauplii of marine calanoid copepods. J. Plankton Res. 14 (12), 1631-1643. https://doi.org/10.1093/plankt/14.12.1631.

Hansen, P.J., 1989. The red tide dinoflagellate Alexandrium tamarense: effects on behaviour and growth of a tintinnid ciliate. Marine Ecol.-Progress Ser. 53, 105-116. https://doi.org/10.3354/meps053105.

Hansen, B., Berggreen, U.C., Tande, K.S., Eilertsen, H.C., 1990. Post-bloom grazing by Calanus glacialis, $C$. finmarchicus and $C$. hyperboreus in the region of the Polar Front, Barents Sea. Mar. Biol. 104, 5-14. https://doi.org/10.1007/BF01313151.

Henriksen, C., Saiz, E., Calbet, A., Hansen, B., 2007. Feeding activity and swimming patterns of Acartia grani and Oithona davisae nauplii in the presence of motile and non-motile prey. Mar. Ecol.-Progress Ser. 331, 119-129. https://doi.org/10.3354/ meps33119.
Iversen, M.H., Poulsen, L.K., 2007. Coprorhexy, coprophagy, and coprochaly in the copepods Calanus helgolandicus, Pseudocalanus elongatus, and Oithona similis. Mar. Ecol. Prog. Ser. 350, 79-89. https://doi.org/10.3354/meps07095.

Juul-Pedersen, T., Arendt, K.E., Mortensen, J., Blicher, M.E., Søgaard, D.H., Rysgaard, S., 2015. Seasonal and interannual phytoplankton production in a sub-Arctic tidewater outlet glacier fjord, SW Greenland. Mar. Ecol. Prog. Ser. 524, 27-38. https://doi.org/ 10.3354/meps11174.

Kanhai, L.D.K., Officer, R., Lyashevska, O., Thompson, R.C., O’Connor, I., 2017. Microplastic abundance, distribution and composition along a latitudinal gradient in the Atlantic Ocean. Mar. Pollut. Bull. 115, 307-314. https://doi.org/10.1016/j. marpolbul.2016.12.025.

Kiørboe, T., 2003. High turnover rates of copepod fecal pellets due to Noctiluca scintillans grazing. Mar. Ecol. Prog. Ser. 258, 181-188. https://doi.org/10.3354/meps258181.

Law, K.L., Thompson, R.C., 2014. Microplastics in the seas. Science 345, 144-145. https://doi.org/10.1126/science.1254065.

Leu, E., Mundy, C.J., Assmy, P., Campbell, K., Gabrielsen, T.M., Gosselin, M., JuulPedersen, T., Gradinger, R., 2015. Arctic spring awakening - steering principles behind the phenology of vernal ice algal blooms. Prog. Oceanogr. 139, 151-170. https://doi.org/10.1016/j.pocean.2015.07.012.

Levinsen, H., Turner, J.T., Nielsen, T.G., Hansen, B.H., 2000. On the trophic coupling between protists and copepods in Arctic marine Ecosystems. Mar. Ecol. Prog. Ser. 204, 65-77. https://doi.org/10.3354/meps204065.

Liu, P., Zhan, X., Wu, X., Li, J., Wang, H., Gao, S., 2020. Effect of weathering on environmental behavior of microplastics: Properties, sorption and potential risks. Chemosphere 242, 125193. https://doi.org/10.1016/j.chemosphere.2019.125193.

Loosanoff, V.L., 1945. Precocious gonad development in oysters induced in midwinter by high temperature. Science 102, 124-125. https://doi.org/10.1126/ science.102.2640.124.

Lusher, A., Tirelli, V., O'Connor, I., Officer, R., 2015. Microplastics in Arctic polar waters: the first reported values of particles in surface and sub-surface samples. Sci. Rep. 5, 14947 https://doi.org/10.1038/srep14947.

Maar, M., Nielsen, T.G., Richardson, K., Christaki, U., Hansen, O.S., Zervoudaki, S., Christou, E.D., 2002. Spatial and temporal variability of food web structure during spring bloom in the Skagerrak. Mar. Ecol. Prog. Ser. 239, 11-29. https://doi.org/ 10.3354/meps239011.

Madsen, S.J., Nielsen, T.G., Tervo, O.M., Söderkvist, J., 2008. Importance of feeding for egg production in Calanus finmarchicus and C. glacialis during the Arctic spring. Mar. Ecol. Prog. Ser. 353, 177-190. https://doi.org/10.3354/meps07129.

Melia, N., Haines, K., Hawkins, E., 2016. Sea ice decline and $21^{\text {st }}$ century trans-Arctic shipping routes. Geophys. Res. Lett. 43, 9720-9728. https://doi.org/10.1002/ 2016GL069315.

Moore, C.J., 2008. Synthetic polymers in the marine environment: a rapidly increasing, long-term threat. Environ. Res. 108 (2), 131-139. https://doi.org/10.1016/j. envres.2008.07.025.

Nielsen, T.G., Hansen, B.W., 1995. Plankton community structure and carbon cycling on the western coast of Greenland during and after the sedimentation of a Diatom Bloom. Mar. Ecol. - Progress Ser. 125, 239-257. https://doi.org/10.3354/ meps125239.

Nielsen, T.G., Kjellerup, S., Smolina, I., Hoarau, G., Lindeque, P., 2014. Live discrimination of Calanus glacialis and C. finmarchicus females: can we trust phenological differences? Mar. Biol. 161 (6), 1299-1306. https://doi.org/10.1007/ s00227-014-2419-5.

Obbard, R.W., Sadri, S., Wong, Y.Q., Khitun, A.A., Baker, I., Thompson, R.C., 2014. Global warming releases microplastic legacy frozen in Arctic Sea ice. Earths Fut. 2, 315-320. https://doi.org/10.1002/2014EF000240.

Paffenhöfer, G., Knowles, S.C., 1978. Feeding of marine planktonic copepods on mixed phytoplankton. Mar. Biol. 48, 143-152. https://doi.org/10.1007/BF00395014.

Paffenhöfer, G.A., Strickland, J.D.H., 1970. A note on the feeding of Calanus helgolandicus on detritus. Mar. Biol. 5, 97-99. https://doi.org/10.1007/BF00352591.

Peeken, I., Primpke, S., Beyer, B., Gütermann, J., Katlein, C., Krumpen, T., Bergmann, M., Hehemann, L., Gerdts, G., 2018. Arctic sea ice is an important temporal sink and means of transport for microplastic. Nat. Commun. 9, 1505. https://doi.org/ 10.1038/s41467-018-03825-5.

Raju, P., Gunabal, S., Santhanam, P., 2019. The impact of microplastics on Marine copepods. In: Santhanam, P., Begum, A., Pachiappan, P. (Eds.), Basic and Applied Zooplankton Biology. Springer, Singapore. https://doi.org/10.1007/978-981-107953-5_19.

Rist, S., Vianello, A., Winding, M., Nielsen, T.G., Almeda, R., Rodríguez-Torres, R., Vollertsen, J., 2020. Quantification of plankton-sized microplastics in a productive coastal Arctic marine ecosystem. Environ. Pollut. 266, 115248 https://doi.org/ 10.1016/j.envpol.2020.115248.

Rysgaard, S., Nielsen, T.G., Hansen, B.W., 1999. Seasonal variation in nutrients, pelagic primary production and grazing in a high-Arctic coastal marine ecosystem, Young Sound, Northeast Greenland. Mar. Ecol. Prog. Ser. 179, 13-25. https://doi.org/ 10.3354/meps179013.

Schiavo, S., Oliviero, M., Romano, V., Dumontet, S., Manzo, S., Liu, G., 2018. Ecotoxicological assessment of Virgin plastic pellet leachates in freshwater matrices. J. Environ. Account. Manag. 6, 345-353. https://doi.org/10.5890/ JEAM.2018.12.007.

Schreck, C.B., Contreras-Sanchez, W., Fitzpatrick, M.S., 2001. Effects of stress on fish reproduction, gamete quality, and progeny. Aquaculture (Amst. Neth.) 197 (1/4), 3-24. https://doi.org/10.1016/s0044-8486(01)00580-4.

Setälä, O., Fleming-Lehtinen, V., Lehtiniemi, M., 2014. Ingestion and transfer of microplastics in theplanktonic food web. Environ. Pollut. 185, 77-83. https://doi. org/10.1016/j.envpol.2013.10.013. 
Seuront, Laurent, 2018. Microplastic leachates impair behavioural vigilance and predator avoidance in a temperate intertidal gastropod. Biol. Lett. 14 https://doi. org/10.1098/rsbl.2018.0453, 20180453.

Song, Y.K., Hong, S.H., Jang, M., Han, G.M., Rani, M., Lee, J., Shim, W.J., 2015 A comparison of microscopic and spectroscopic identification methods for analysis of microplastics in environmental samples. Mar. Pollut. Bull. 93, 202-209. https://doi. org/10.1016/j.marpolbul.2015.01.015.

Stroeve, J.C., Serreze, M.C., Holland, M.M., Kay, J.E., Malanik, J., Barrett, A.P., 2012. The Arctic's rapidly shrinking sea ice cover: a research synthesis. Clim. Change 110 1005-1027. https://doi.org/10.1007/s10584-011-0101-1.

Sun, X., Li, Q., Zhu, M., Liang, J., Zheng, S., Zhao, Y., 2017. Ingestion of microplastics by natural zooplankton groups in the northern South China Sea. Mar. Pollut. Bull. 115, 217e224 https://doi.org/10.1016/j.marpolbul.2016.12.004.

Swalethorp, R., Kjellerup, S., Dünweber, M., Nielsen, T.G., Møller, E.F., Rysgaard, S., Hansen, B.W., 2011. Grazing, egg production, and biochemical evidence of differences in the life strategies of Calanus finmarchicus, C. glacialis and C. hyperboreusin Disko Bay, western Greenland. Mar. Ecol.-Progress Ser. 429, 125-144. https://doi.org/10.3354/meps09065.

Tang, K.W., Nielsen, T.G., Munk, P., Mortensen, J., Møller, E.F., Arendt, K.E., Tönnesson, K., Pedersen, T.J., 2011. Community structure and trophodynamics of mesozoo-plankton along a melt water influenced Greenlandic fjord Marine. Ecol. Progress Ser. 434, 77-90. https://doi.org/10.3354/meps09188.

Turner, J.T., 2015. Zooplankton fecal pellets, marine snow, phytodetritus and the ocean's biological pump. Prog. Oceanogr. 130, 205-248. https://doi.org/10.1016/j. pocean.2014.08.005.

Varpe, Ø., Jørgensen, C., Tarling, G.A., Fiksen, Ø., 2009. The adaptive value of energy storage and capital breeding in seasonal environments. Oikos 118, 363-370. https:// doi.org/10.1111/j.1600-0706.2008.17036.x.

Visser, A.W., Grønning, J., Jónasdóttir, S.H., 2017. Calanus hyperboreus and the lipid pump. Limnol. Oceanogr. 62, 1155-1165. https://doi.org/10.1002/lno.10492.

Vroom, R.J., Koelmans, A.A., Besseling, E., Halsband, C., 2017. Aging of microplastics promotes their ingestion by marine zooplankton. Environ. Pollut. 231, 987-996. https://doi.org/10.1016/j.envpol.2017.08.088.

Weidick, A., Bennike, O., Citterio, M., Nørgaard-Pedersen, N., 2012. Neoglacial and historical glacier changes around Kangersuneq fjord in southern West Greenland. GEUS Bull. 27, 1-68. https://doi.org/10.34194/geusb.v27.4694.

Wieczorek, A.M., Croot, P.L., Lombard, F., Sheahan, J.N., Doyle, T.K., 2019. Microplastic Ingestion by Gelatinous Zooplankton May Lower Efficiency of the Biological Pump. Environ. Sci. Technol. 53 (9), 5387-5395. https://doi.org/10.1021/acs.est.8b07174. 